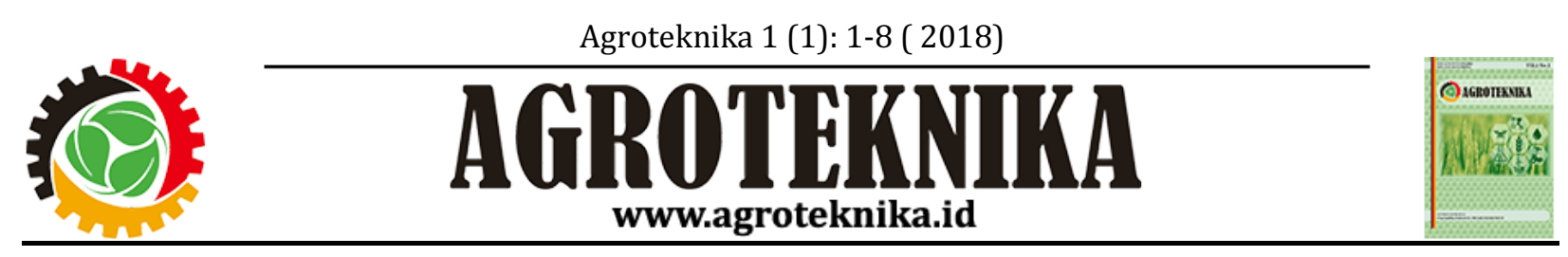

\title{
Rancang Bangun Alat Pencacah Daun dan Ranting Gambir
}

\section{Design and Building of Leaves and Gambir Branchs Chopper}

Muhammad Awal Nasution*, Geri Putra, Adito Putra, Satria Andika, Aziz Zuhdi

Program Studi Mesin dan Peralatan Pertanian, Politeknik Pertanian Negeri Payakumbuh

\author{
${ }^{*}$ Penulis Korespondensi \\ Email: muhammadawa1006@gmail.com
}

\begin{abstract}
Abstrak. Tanaman Gambir merupakan tanaman perdu yang memiliki nilai ekonomis tinggi. Ekstrak (getah) daun dan ranting gambir mengandung asam katechu tannat (tanin), katechin, pyrocatechol, florisin dan lilin fixed oil. Sumatera Barat merupakan penghasil gambir terbesar di Indonesia namun bila dilihat dari produktivitas per hektar masih rendah yaitu berkisar antara 300 sampai $400 \mathrm{~kg}$ gambir kering per hektar per tahun. Hal ini disebabkan pengolahan gambir yang masih tradisional. Salah satu solusi untuk mengatasi permasalahan diatas adalah dengan dibuatnya alat pencacah daun dan ranting gambir. Alat pencacah daun dan ranting gambir ini diharapkan dapat mempermudah masyarakat dalam proses pengempaan karena daun dan ranting gambir sudah dicacah terlebih dahulu. Kapasitas alat pencacah ini adalah 53,83 kg/jam dan laju pengumpanan 63,6 kg/jam. Untuk analisa ekonomi teknik didapat total biaya tetap Rp.1.911.052/tahun, total biaya tidak tetap Rp. 91.088,8 / jam, biaya sewa alat Rp. 1.706,9/jam dan BEP untuk pengoperasionalan alat 2.365,45 Kg/jam. Harga jual alat pencacah daun dan ranting gambir adalah $R$ p. 7.463 .000 dengan laba $30 \%$.
\end{abstract}

Kata kunci: gambir, pencacah, uji kinerja

Abstract. Gambir plants are shrub plants that have high economic value. Leaf extract and gambir branches contain katechu tannat (tannin), katechin, pyrocatechol, florisin and fixed oil candles. West Sumatra is the largest gambir producer in Indonesia, but in case of productivity, it is still low, ranging from 300 to $400 \mathrm{~kg}$ of dried gambier per hectare per year. This is due to the traditional processing of gambir. One solution to overcome the above problems is to make leaf and branch of gambir chopping machine. The leaf chopper and gambir branch is expected to facilitate the farmer in the pressing process. The capacity of this chopper is $53.83 \mathrm{~kg} / \mathrm{hour}$ and the feed rate is $63.6 \mathrm{~kg} / \mathrm{hour}$. For technical economic analysis, the total fixed costs of Rp. 1,911,052 / year are obtained, the total non-fixed costs of Rp. 91,088.8 / hour, the cost of renting equipment is Rp. 1,706.9 / hour and BEP for operation of 2,365.45 Kg / hour. Leaf and gambir branch chopper are Rp. 7,463,000 with 30\% profit.

Keywords: gambir, chopper, performance test

\section{Pendahuluan}

Tanaman gambir merupakan tanaman perdu famili Rubiace (kopi-kopian) yang memiliki nilai ekonomi tinggi. Ekstrak (getah) daun dan ranting gambir mengandung asam katechu tannat (tanin), katechin, pyrocatecol, florisin, lilin dan fixed oil. Kandungan utama gambir adalah asam katechu tannat (20-50\%), katechin (7-33\%), pyrocatechol (20-30\%) dan bahan lain yang ada dalam jumlah terbatas. Kandungan kimia gambir yang paling banyak dimanfaatkan adalah katechin dan tanin (Rahmawati, 2009). Gambir (Uncaria gambir) merupakan salah satu 
komoditas perkebunan rakyat yang berorientasi ekspor, dimana Indonesia adalah negara pemasok utama gambir dunia (80\%) (Isnawati,2010).

Indonesia sebagai pemasok utama gambir dunia, memperoleh sebagian besar gambir dari daerah Provinsi Sumatera Barat (Djanun, 1998) yang diekspor ke Banglades, India, Pakistan, Taiwan, Jepang, Korea Selatan, Perancis dan Swiss (Denian, 2002). Sumatera Barat merupakan penghasil gambir terbesar di Indonesia namun bila dilihat dari produktivitas per hektar, produksi gambir masih rendah, yaitu berkisar antara 300 sampai $450 \mathrm{~kg}$ gambir kering per hektar per tahun. Sedangkan potensi hasilnya $2.100 \mathrm{~kg}$ gambir kering per hektar per tahun. Rendahnya produktivitas ini adalah akibat teknik budidaya dan teknik pengolahan yang masih tradisional (Denian, 2004).

Pengolahan hasil masih dilakukan dengan menggunakan teknologi yang sangat sederhana dan jauh tertinggal salah satunya pada proses perajangan. Perajangan pada daun dan ranting gambir sebelum proses perebusan mampu meningkat hasil dari ekstrak getah gambir hingga 10\% daripada tanpa dilakukan perajangan. Proses perajangan dilakukan menggunakan lesung sehingga perajangan akan menghabiskan waktu yang lama dan tidak efektif dalam pelaksanaannya (Risfaheri \& Yanti, 1993). Selain itu rendemen (ekstrak) yang diperoleh juga kurang optimal. Sarif et al, (2018) telah merancang dan melakukan pencacah daun dan ranting gambir dengan tipe roler. Penelitian ini memiliki kapasitas $8,45 \mathrm{~kg} / \mathrm{jam}$.

Dari uraian di atas dapat disimpulkan untuk mengaplikasikan tahap pencacahan daun dan ranting gambir untuk meningkatkan ekstrak getah daun gambir yang lebih banyak yaitu dengan cara merancang alat pencacah daun dan ranting gambir yang mampu meningkatkan nilai ekonomi dan mengefisiensi waktu. Dengan adanya alat pencacah daun dan ranting gambir diharapkan dapat mengoptimalkan rendemen dan penggunaan waktu.

\section{Bahan dan Metode}

\section{Alat dan Bahan}

Alat yang digunakan dalam proses pembuatan alat pencacah daun dan ranting gambir adalah mesin las, mesin bubut, gerinda potong, gerinda kecil, meteran $7 \mathrm{~m}$, siku-siku, jangka sorong, brandel porong.

Bahan yang digunakan dalam pembuatan alat pencacah daun dan ranting gambir ini adalah besi UNP $100 \mathrm{~mm}$, besi strip $5 \mathrm{~mm}$ X $40 \mathrm{~mm}$ X $100 \mathrm{~mm}$, besi UNP $50 \mathrm{~mm}$, besi poros $\varnothing 11 / 4$ inci, plat baja $1,8 \mathrm{~mm}$, bantalan 2 inci, puli $\varnothing 6$ inci, sabuk, baut $14 \mathrm{~mm}$, elektroda $\varnothing 2,6$ dan kedudukan bantalan.

\section{Metoda Pelaksanaan}

Hal yang perlu dilakukan sebelum pembuatan alat pencacah daun dan ranting gambir adalah mengidentifikasi masalah, mencari ide untuk memecahkan masalah dan mengkaji 
kelayakan ide. Selanjutnya menyempurnakan ide dengan mendesain gambar alat, kemudian menyusun komponen menjadi satu unit alat.

Tahap selanjutnya adalah uji fungsional dari komponen-komponen alat apakah komponen dapat bekerja sesuai fungsinya. Jika tidak berfungsi baik maka dilakukan perbaikan, jika berfungsi baik akan dilanjutkan ke uji kinerja. Pada saat uji kinerja, jika alat bekerja tidak sesuai dengan standar uji kinerja maka perlu dilakukan modifikasi dan uji fungsional kembali, jika kinerja memenuhi standar maka alat siap dioperasikan. Diagram alir tahap pembuatan alat pencacah daun dan ranting gambir dapat dilihat pada Gambar 1.

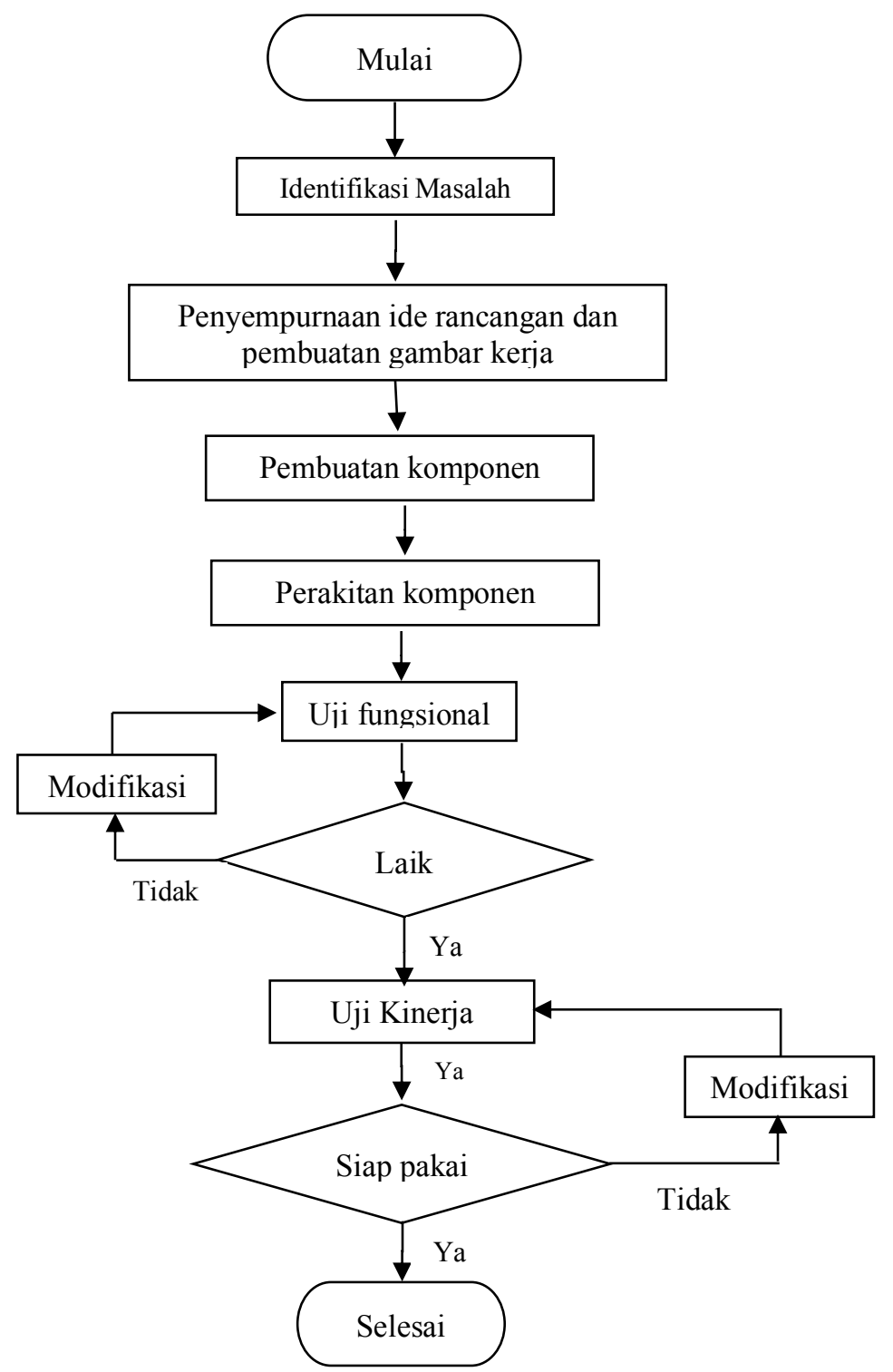

Gambar 1. Diagram alir tahapan pembuatan alat pencacah daun dan ranting gambir

\section{Rancangan Alat Pencacah Daun dan Ranting Gambir}

Berikut rancangan stuktural dan fungsional alat pencacah daun dan ranting gambir : 


\section{Hopper}

Hopper (Corong pemasukkan) dan talam penyalur terbuat dari plat hitam 1,8 mm dengan dimensi seperti pada gambar dalam satuan cm. Hopper dapat dilihat pada Gambar 2.

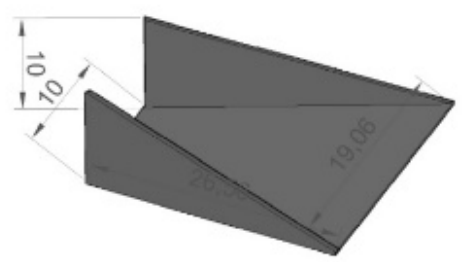

Gambar 2. Hopper

Pisau-pisau pencacah

Komponen pencacah terdiri dari pisau-pisau dan sisir-sisir yang terbuat dari besi strip yang tajam. Pisau-pisau ini merupakan tipe engsel dengan ukuran panjang pisau $15 \mathrm{~cm}$, jarak antar pisau $3 \mathrm{~cm}$, dengan jumlah keseluruhan mata pisau 36 buah dengan panjang besi porosnya 65 $\mathrm{cm}$. Dimensi pisau pencacah seperti pada gambar dibawah dalam satuan $\mathrm{cm}$. Pisau-pisau pencacah dapat dilihat pada Gambar 3.

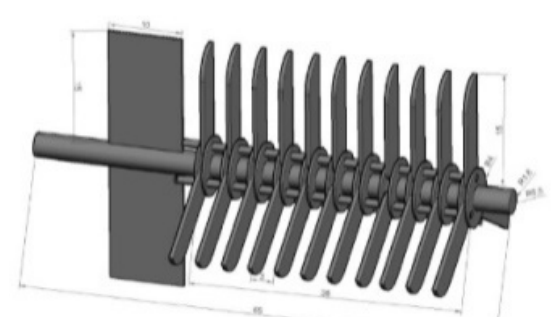

Gambar 3. Pisau-pisau pencacah

Rangka

Rangka yang terbuat dari besi U $500 \mathrm{~mm}$. Kerangka utama terbuat dari besi siku berukuran $3 \mathrm{~cm}$, panjang kerangka mesin $60 \mathrm{~cm}$, lebar $45 \mathrm{~cm}$ dan tinggi $45 \mathrm{~cm}$. Rangka dapat dilihat pada Gambar 4.

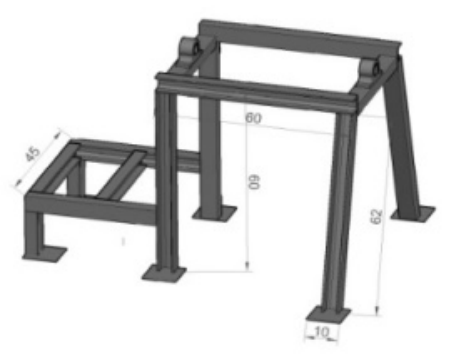

Gambar 4. Unit rangka

Talam penyalur

Talam penyalur merupakan bagian untuk menyalurkan hasil cacahan. Terbuat dari besi plat $2 \mathrm{~mm}$ dengan dimensi yang tertera pada Gambar 5. 


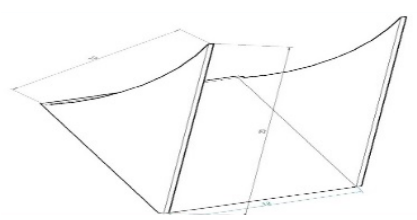

Gambar 5. Talam penyalur

Puli dan sabuk

Sistem transmisi untuk penyaluran tenaga dari motor ke pisau pisau menggunakan pulley dan sabuk dengan dimensi yang tertera pada Gambar 6 .

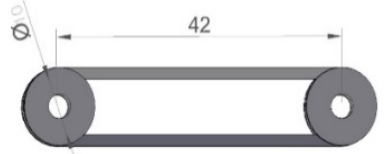

Gambar 6. Puli dan sabuk

Tabung pencacah

Tabung pencacah terbuat dari plat dengan ketebalan $2 \mathrm{~mm}$, diameter tabung $38 \mathrm{~cm}$, dan panjang $50 \mathrm{~cm}$. Tabung pencacah dapat dilihat Gambar 7 .

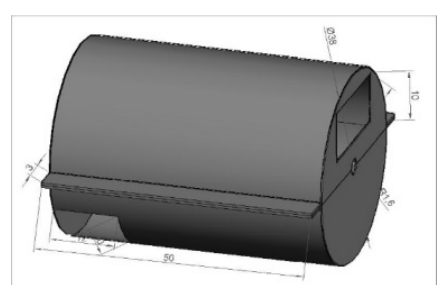

Gambar 7. Tabung pencacah

Mesin diesel

Sumber tenaga alat pencacah daun dan ranting gambir adalah mesin diesel dengan daya 8 HP. Gambar mesin dapat dilihat pada Gambar 8.

\section{Bantalan}

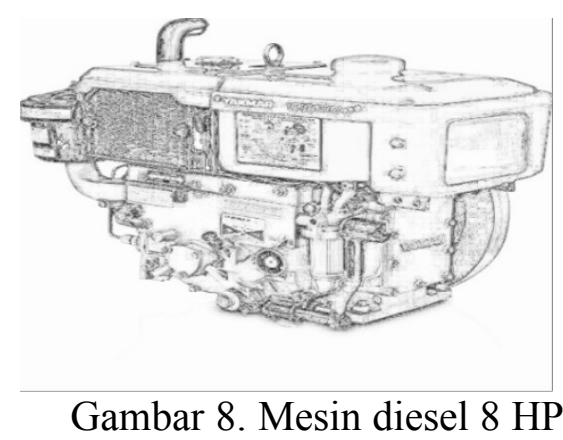

Bantalan yang digunakan adalah bantalan UCP 205. Bantalan dapat dilihat pada Gambar 9.

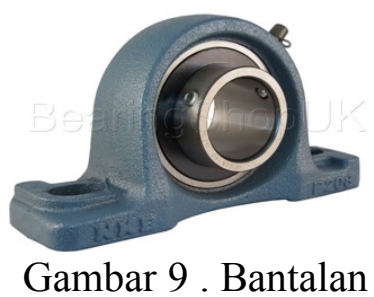




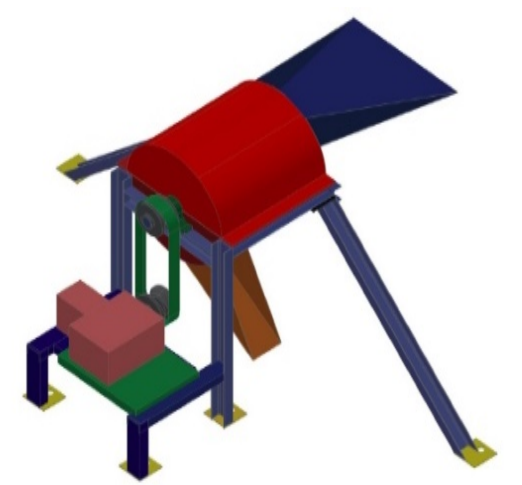

Gambar 10. Gambar utuh alat pencacah daun dan ranting gambir

\section{Hasil dan Pembahasan}

\section{Uji Kinerja}

Dari hasil pengujian mesin yang dilakukan dapat dihitung laju pengumpanan, kapasitas alat, rendemen dan kualitas cacahan sebagai berikut.

Laju pengumpanan

Laju pengumpanan adalah jumlah dari seluruh bahan dibagi dengan waktu yang dibutuhkan selama pengolahan atau pencacahan daun dan ranting gambir. Data pengujian dapat dilihat pada Tabel 1 .

Tabel 1. Laju pengumpanan

\begin{tabular}{llrrrc}
\hline \multirow{2}{*}{ No } & \multicolumn{1}{c}{ Uraian } & \multicolumn{3}{c}{ Pengujian } & \multirow{2}{*}{ Rata-rata } \\
& & I & II & III & \\
\hline 1 & Berat bahan $(\mathrm{Kg})$ & 10 & 10 & 10 & 10 \\
2 & Waktu (Jam) & 0.16 & 0.15 & 0.16 & 0.156 \\
3 & Laju pengumpanan $(\mathrm{Kg} / \mathrm{Jam})$ & 62.5 & 66.7 & 62.5 & 63.9 \\
\hline
\end{tabular}

Dari tabel pengujian diatas hasil rata - rata dapat dihitung laju pengumpanannya adalah:

Laju pengumpanan $=\frac{10 \mathrm{Kg}}{0.156 \mathrm{jam}}=63,9 \mathrm{Kg} / \mathrm{Jam}$

Kapasitas alat

Kapasitas alat adalah kemampuan alat untuk menghasilkan cacahan daun dan ranting gambir dalam waktu yang ditentukan. Data pengujian dapat dilihat pada Tabel 2.

Tabel 2. Kapasitas alat

\begin{tabular}{llcccc}
\hline \multirow{2}{*}{ No } & \multirow{2}{*}{ Uraian } & \multicolumn{3}{c}{ Pengujian } & Rata- \\
& & I & II & III & rata \\
\hline 1 & Berat bahan yang sudah dicacah $(\mathrm{Kg})$ & 9.15 & 9.15 & 9.15 & 9.15 \\
2 & Waktu (Jam) & 0.16 & 0.15 & 0.16 & 0.156 \\
3 & Kapasitas $(\mathrm{Kg} / \mathrm{Jam})$ & 57.18 & 61 & 57.18 & 58.45 \\
\hline
\end{tabular}

Kapasitas alat $=\frac{9.15 \mathrm{Kg}}{0.156 \mathrm{jam}}=58,45 \mathrm{Kg} / \mathrm{Jam}$

Rendemen pencacahan $(\mathrm{Sr})$

$\mathrm{Sr}=\frac{\mathrm{Wp}}{\mathrm{Wo}} \times 100 \%=\frac{9.15 \mathrm{Kg}}{10 \mathrm{Kg}} \times 100 \%=91,5 \%$ 
Kualitas cacahan

Menurut SKKNI kode unit : THP.ZR02.060.01 peralatan berkaitan dengan pencacahan umumnya berupa mesin pencacah (Chopper) dengan pisau pemotong pencacah, atau mesin pencacah model hammer mill, berbeda dengan proses grinding (penggilingan) yang menghasilkan bentuk tepung, hasil cacahan umumnya berukuran kasar (3-5 mm). Dari pernyataan diatas hasil cacahan alat ini melebihi dari standar tersebut yakni berukuran 5-10 mm.

\section{Hasil Analisa Ekonomi}

Analisa ekonomi yang serupa telah diterapkan pada penelitian: Sarif et al, (2018) dan Herdian et al, (2019). Asumsi yang digunakan pada biaya operasional alat pencacah daun dan ranting gambir dapat dihitung sebagai berikut:
a. Harga jual alat $(\mathrm{P}) \quad=$ Rp. 11.596 .000
b. Umur ekonomis $(\mathrm{N})=5$ tahun
c. Harga akhir (S) $\quad=10 \% \times \mathrm{P}$
d. Bunga akhir (i) $\quad=12 \% /$ Tahun
e. Jam kerja /Tahun $(X)=2.688$ jam / tahun
f. Jam kerja/hari $\quad=8$ jam
g. Upah operator $\quad=$ Rp. $50.000 /$ hari
h. Jumlah operator $\quad=3$ orang
i. Upah/Sewa alat $\quad=50000 /$ hari

\section{Biaya tetap}

Biaya penyusutan $(\mathrm{D})=\frac{\mathrm{P}-\mathrm{S}}{\mathrm{N}}=\frac{11.596 .000-1.159 .600}{5}=$ Rp. $2.087 .280 /$ tahun

Bunga modal $(\mathrm{I})=\frac{\mathrm{i}(\mathrm{P})(\mathrm{N}+\mathrm{I})}{2 \mathrm{n}}=\frac{12 \%(\mathrm{Rp} .11 .596 .000)(5+1 \mathrm{I})}{2 \times 5}=$ Rp. 834.912/tahun

Total Biaya tetap $=$ Biaya penyusutan + Bunga modal

$$
=\text { Rp.2.087.280/tahun }+ \text { Rp.834.912/tahun }=\text { Rp. 2.922.192/tahun }
$$

\section{Biaya tidak tetap}

Upah operator $=\frac{\text { upah }(\mathrm{Rp}) / \mathrm{harix} \text { jumlah operator }}{\text { jam kerja } / \text { hari }}=\frac{\text { Rp.50000/hari x } 3}{8 \text { jam } / \text { hari }}=\mathrm{Rp} \cdot 18.750 / \mathrm{jam}$

Biaya perawatan $=\frac{1,2 \% \mathrm{x}(\mathrm{P}-\mathrm{S})}{1000 \mathrm{jam}}=\frac{1,2 \% \mathrm{x}(11.596 .000-1.159 .600)}{1000 \mathrm{jam}}=\mathrm{Rp} \cdot 1.252,368 / \mathrm{jam}$

Biaya bahan bakar $=10 \%$ x BHP x Harga $=10 \%$ × 8 × $6.500=$ Rp. 5.200/jam

Biaya tidak tetap $=$ Upah operator + Biaya perawatan + Biaya bahan bakar

$$
=\text { Rp. } 18.750 / \mathrm{jam}+\mathrm{Rp} 1.252,368 / \mathrm{jam}+\mathrm{Rp} .5 .200 / \mathrm{jam}=\mathrm{Rp} .149,318 / \mathrm{jam}
$$

\section{Biaya pokok}

$\mathrm{BP}=\frac{\frac{\mathrm{BT}}{\mathrm{x}}+\mathrm{BTT}}{\mathrm{C}}=\frac{\frac{2.922 .192}{2.688 \mathrm{jam}}+149,318}{58.45 \frac{\mathrm{kg}}{\mathrm{jam}}}=\frac{150.405 .125}{58.45 \frac{\mathrm{kg}}{\mathrm{jam}}}=\mathrm{Rp.} 2.573 / \mathrm{Kg}$ 


\section{Break event point (BEP)}

$\mathrm{BEP}=\frac{\mathrm{BT}}{\mathrm{R}-\left(\frac{\mathrm{BTT}}{\mathrm{C}}\right)}=\frac{2.922 .192}{50000 / \text { hari }-\left(\frac{149,318}{58,45}\right)}=\frac{2.922 .192}{49,997445}=558,892 \mathrm{Kg} / \mathrm{Tahun}$

\section{Analisa $\mathrm{B} / \mathrm{C}$ ratio}

$\frac{\mathrm{B}}{\mathrm{C}}$ Ratio $=\frac{\text { Harga Jual }}{\text { Biaya Total }}=\frac{R p \cdot 11.596 .000}{\text { Rp.8.920.000 }}=1,3$

Dengan demikian didapat biaya total pembuatan alat pencacah daun dan ranting gambir ini adalah Rp. 8.920.000, harga jual Rp. 11. 596.000, biaya tetap Rp. 2.922.192/tahun, biaya tidak tetap Rp. 149,318/jam, biaya pokok Rp. $2.573 / \mathrm{kg}$, break event point 558,892 kg/tahun dan analisa $\mathrm{B} / \mathrm{C}$ ratio 1,3 .

\section{Kesimpulan}

Alat pencacah daun dan ranting gambir memiliki tinggi $110 \mathrm{~cm}$, lebar $80 \mathrm{~cm}$ dan panjang $120 \mathrm{~cm}$. Kapasitas alat 58,45 kg/jam dan laju pengumpanan $63,6 \mathrm{Kg} / \mathrm{Jam}$. Analisa biaya total pembuatan alat pencacah daun dan ranting gambir adalah Rp. 8.920.000, harga jual Rp. 11 . 596.000, biaya tetap Rp. 2.922.192 /tahun, biaya tidak tetap Rp. 149,318/jam, biaya pokok Rp. $2.573 / \mathrm{kg}$, BEP (Break Event Point) 558,892 kg/tahun dan analisa B/C ratio 1,3.

\section{Daftar Pustaka}

Djanun, L.N.C. (1998). Peluang Ekspor Gambir di Pasar Internasional: BPEN. Jakarta : Depperindak.

Denian, A. (2002). Potensi Pengembangan Budidaya dan Peluang Agribisnis Gambir. Prosiding Seminar Nasional Ketahanan Pangan dan Agribisnis. PSE. Padang 21-22 November 2000. pp. 110-116.

Denian, A. (2004). Status Teknologi Produksi Tanaman Gambir. Makalah Utama Padang Expres Teknologi Gambir, Kayumanis dan Atsiri, Laing Solok, 2 Desember 2004. Solok : Balai Penelitian Rempah dan Obat Laing Solok.

Herdian, F., Jabbar, R., Batubara, F., Zulnadi, Z., Anas, I., \& Yudistira, Y. (2019). Rancang Bangun Alat Pengaduk Kerupuk Adonan Tipe Horizontal. Journal of Applied Agricultural Science and Technology, 3(1), 157-165. https://doi.org/10.32530/jaast.v3i1.84

Isnawati, A. (2010). Analisis Kualitatif dan Kuantitatif Senyawa Katekin dan Kuersetin pada 3 Mutu Ekstrak Gambir. Pusat Penelitian dan Pengembangan Biomedis dan Farmasi Badan Penelitian dan Pengembangan Kesehatan Departemen Kesehatan RI. Jakarta.

Rahmawati, (2009). Kajian Tentang Pengaruh Beberapa Perlakuan Daun/Ranting Tanaman Gambir (Unciria Gambir Roxb) Sebelum Proses Extraksi Terhadap Perubahan Anatomi Daun dan Karakteristik Gambir Kering. [Tesis]:Padang:Universitas Andalas.

Risfaheri \& Yanti L. (1993). Pengaruh Ketuaan Daun dan Penanganan Daun Sebelum Pengempaan Terhadap Rendemen dan Mutu Gambir. Buletin Penelitian Rempah dan Obat. vol. 8 (1) : 46-51.

Sarif, R., Afif, M.I, Ramadhan, G., Hendra, H., Irzal, I., Anas, I., \& Djinis, M. (2018). Analisa Ekonomi dan Uji Kinerja pada Mesin Pencacah Daun dan Ranting Gambir Tipe Roller. Journal of Applied Agricultural Science and Technology, 2(1), 1-10. https://doi.org/10.32530/jaast.v2i1.12 